\title{
The End of Leisure: Are Preferred Leisure Activities Contraindicated for Education-Related Stress/Anxiety Reduction?
}

\author{
Beth Daly and L. L. Morton \\ Faculty of Education, University of Windsor, 401 Sunset Avenue, Windsor, ON, Canada N9B 3P4 \\ Correspondence should be addressed to Beth Daly, bethdaly@uwindsor.ca \\ Received 15 October 2010; Accepted 4 March 2011 \\ Academic Editor: Miriam David
}

Copyright ( $) 2011$ B. Daly and L. L. Morton. This is an open access article distributed under the Creative Commons Attribution License, which permits unrestricted use, distribution, and reproduction in any medium, provided the original work is properly cited.

\begin{abstract}
Teacher stress is an increasing problem not only for practicing teachers but for student teachers as well. It leads to professional teachers leaving the profession, and future teachers enduring much stress and anxiety throughout teacher education programs. To further explore effects of stress, teacher candidates were surveyed with respect to (1) the role of their leisure preferences and (2) their stress levels related to Pedagogy, Evaluation, Class Management, and Interpersonal Relations. In Study One $(n=216)$, a profile of leisure preferences was comprised, and findings from the relationship between leisure preferences and teaching anxieties contributed to a profile to explore reduced anxiety over time. A follow-up investigation (Study Two, $n=136$ ) tested the discriminatory potential of these leisure profile variables to separate those who showed less anxiety over time from those who regressed. Surprisingly, increased anxiety was associated with higher leisure in Sports, Adventure, Travel, and Exotica and with non-Science majors, Human Kinesiology majors, and Males. Some leisure preferences appear to be counterintuitive, given commonsense notions of the value of leisure. A Leisure Preferences Profile serves to facilitate discrimination between groups (improvement in anxiety levels versus no improvement) with respect to Pedagogical and Evaluation anxiety. A Composite Profile suggests that Leisure preferences related to Sports, Adventure, and Exotica are counterproductive in reducing stress related to Pedagogy. Implications are discussed.
\end{abstract}

\section{Introduction}

Teacher stress has compromised the educational field—and literature-for decades, seemingly with increasing frequency [1]. In fact, many practicing teachers experience stress from the very onset of their careers as teacher candidates. As early as 1952, anxiety has been cited as a problem for student teachers [2]. Indeed, preservice teachers characteristically experience stress and anxiety throughout their training programs [3-7]. Other studies support the claim that students preparing for careers in teaching experience stress throughout their education and training programs [8-10]. As such, it is incumbent upon educators and researchers to examine underlying factors that lead to such extremes as "burnout" and to consider and examine ways in which educators can develop coping behaviours in order to manage the onset of stress.

The problem appears to be a global one. Bachkirova [11] points to the international problem of practicing teachers leaving the profession, often within the first five years of their career. Not only does stress impact educators, but reportedly affects classroom students as well [12]. One recent study [13] pointed to the overwhelming research on the negative consequences of stress. Others have also examined increasing stress in teachers $[14,15]$, which has become alarmingly high [16]. The prominent stressors that seem to impact teachers the most include such factors as struggles with classroom management and coping strategies [13], cultural differences in classrooms [17], evaluation in the form of constant and unfair subjection to media scrutiny and political criticism [14], and, quite likely, interpersonal relationships related to home and school.

1.1. Definition of Stress. Distinguishing between stress, anxiety, and burnout is helpful for the purposes of this research, particularly since our participants were studied over the course of only eight months, their preservice teaching year. Stress and anxiety are similar and the differences between 
the two minor. For instance Fontana and Abouserie [16] describe anxiety as being associated with the onset of stress, or at least a component of it. However, they are often used interchangeably, without delineating differences. As such, given the short-term situation (8-month program) of the participants in this investigation, we do use the term interchangeably. "Burnout," on the other hand, has been described as a more serious consequence of prolonged stress [18]. Maslach [19] specifically described job burnout as a "psychological syndrome that involves a prolonged response to stressors." Since stress and anxiety are viewed as key precursors to "burnout," a proactive approach to teachers' mental health should address the amelioration of stress and anxiety.

Two research papers in the area of stress and coping strategies $[8,13,19]$ have relied on the same definition of stress. Accordingly, then, stress is defined here as the particular relationship between an individual and the environment, as appraised by the individual to be taxing or exceeding personal resources, and disruptive to daily routines. This definition is well suited for research in the context of educational settings, particularly considering that classroom disruption and behaviour have been cited as being a major stressor to educators, even as far back as six decades $[2,20]$.

1.2. Stress Factors for Preservice Teachers. Many causes of stress and anxiety in preservice teachers have been researched and addressed in the literature $[3,4,7,14]$ and the increasing problem readily suggests that anxiety-reducing measures need be addressed at the preservice teaching level. The demographic, dispositional, and experiential factors related to student-teacher anxieties are manifold [10]. The varied requirements that a preservice teacher must meet within the practice teaching experience alone can be highly stressful. Not surprising, high levels of anxiety have been shown to have debilitating effects not only for preservice teachers but also their corresponding students as well [21]. For instance, the anxiety can have a debilitating effect on students, compromising learning, motivation, and performance and causing disruption in the classroom $[6,21]$. Time management and extensive workload outside classroom hours are also considerable factors for student teachers.

It has been reported that anxiety can be reduced in a number of ways. One study [14] of British preservice teachers reported that they coped with anxiety in both positive and negative ways, including physical activity, praying and attending church, seeking therapy, consuming excessive amounts of alcohol, and even taking Prozac. Others $[6,10]$ have found that simply spending time in the classroom reduces anxiety in student teachers, presumably because of the confidence and/or comfort level that is attained with experience and routine. Morton et al. [10] found that both instructional preparation and practice teaching actually reduced anxiety following field experiences, suggesting that practice teaching in itself may serve as an anxiety-reducing intervention.

Both Head et al. [14] and Gold [4] have suggested reducing anxiety through the development of a systematic stressreduction program and counseling sessions. Munday et al.
[6] examined the effects of a formal stress reduction program for preservice teachers who were enrolled in a secondary and higher education program, but found there were no anxiety-reducing benefits demonstrated as a result. Payne and Manning [21], however, reported that cognitive self-talk, for female preservice teachers, significantly lowered anxiety.

Of course, certain individuals in general may simply be predisposed to anxiety more than others [10]. In a study examining the relationship between personality traits and stress [16], individuals who reportedly had extroverted personalities were lower in stress than those who were reportedly more introverted. It was noted that typical extroverts are sociable, crave excitement, and take chances, which may enable one to respond more effectively to stressful teaching situations. Typical introverts, however, are quieter, less drawn towards excitement, reserved or distant, and more affected by personal events, making stressful teaching situations more consequential. It was also noted that personality characteristics do contribute to stress levels more than demographic variables, such as age and gender.

1.3. Leisure Preferences. Individual leisure interests may also contribute to the reduction of stress and anxiety. Teachers' inability to distance themselves from work may well be a factor in contributing to health problems, and participation in leisure activities may actually reduce burnout [22]. Leisure's potential to be recuperative may also benefit the emotional well-being of an individual [23]. Leisure preferences are defined as hobbies recreational or physical activities that evoke positive feelings or perceptions [24]. Pondé and Santana [25] further characterize leisure as a "perceived freedom" that is motivated by choice.

Leisure preferences have been shown to be beneficial for one's mental health and well-being [25]. Although research examining the relationship between stress and leisure interests is limited, several researchers [26,27] report that leisure interests among specific populations serve to reduce stress levels within the groups. In a study [28] of principals and deputy principals in secondary schools, leisure proved to be an important factor for coping with work-related stress. Patterson [26] found a significant association between involvement in leisure preferences, and stress reduction for those who had recently loss of a spouse. Pondé and Santana [25] examined the benefits of Leisure Preferences as a protection of mental health in women and found that symptoms of anxiety and depression were higher among women who did not participate in leisure preferences than those who did. In one study [27] examining the relationship between leisure and perceived academic stress in college students, it was concluded that lower leisure satisfaction was related to greater anxiety. This resonates with other research [28], which specifically addresses the need for further investigation into leisure as an intervention strategy.

1.4. Present Investigation. The present investigation was comprised of two subsequent studies, the second of which involved participants from the previous one. The first study focused on two research questions. The first question addresses the profile of the preservice teacher participant 
TABLE 1: Three taxonomies for leisure preferences evident in the literature and one generated from factor analysis of the LIC ${ }^{\mathrm{a}}$.

\begin{tabular}{|c|c|c|c|c|}
\hline Scales & LIC Factor Analysis ${ }^{\mathrm{b}}$ & Passmore and French [30] & Overs [31] & Tinsley and Eldredge [32] \\
\hline 1 & Crafts & Achievement leisure & Sports & Agency \\
\hline 2 & Sports & Social leisure & Nature & Novelty \\
\hline 3 & Social activities & Time-out leisure & Art \& Music & Belongingness \\
\hline 4 & House and family & & Organizations & Service \\
\hline 5 & Travel & & Education & Sensual enjoyment \\
\hline 6 & Church work & & Entertainment \& Culture & Cognitive stimulation \\
\hline 7 & Cognitive pursuits & & Volunteer & Self-Expression \\
\hline 8 & Entrepreneurial Business activity & & Games & Creativity \\
\hline 9 & Animal bonding & & Crafts & Competition \\
\hline 10 & Adventure & & Collecting & Vicarious competition \\
\hline 11 & Games & & & Relaxation \\
\hline 12 & Exotica & & & Residual \\
\hline
\end{tabular}

${ }^{a}$ The three literature-based taxonomies are drawn from Mokhtaria, Salomon, and Handy (2004).

${ }^{\text {b}}$ Twelve scales are based on our factor analysis of the LIC [29].

with respect to leisure preferences, and how these preferences link to demographics, social structures, and academic majors. The second question addresses the relationship between leisure preferences and anxieties related to teaching. This information is regarded as a first step in building a leisure-based profile for the purpose of understanding and facilitating anxiety reduction. In the second study, we test the potential of the Profile for discriminating between those preservice teachers who benefit from Leisure Preferences from those who do not. In other words, how/does the Leisure Profile serve a purpose for examining increased and decreased anxiety in student teachers as a function of the leisure activities in which they are most involved?

\section{Study 1}

\subsection{Method}

2.1.1. Subjects. The sample was composed of subjects in a teacher education program where all participants were on a career path for teaching in (1) grades kindergarten through six, Primary-Junior (PJ) $(N=120),(2)$ grades four through 10 , the Junior-Intermediate division (JI) $(N=36)$, or (3) grades seven through 12, the Intermediate-Senior division (IS) $(N=60)$. Of the 216 students, 181 indicated that English was their native language. There were 159 females and 57 males, and ages were categorized in age groups of $21-$ 25 years (54\%), 26-30 (23\%), 31-35 (14\%), and 36 or older $(9 \%)$, and $66 \%$ of the sample were single.

Moreover, while all subjects held at least a Bachelor's degree, 15 reportedly held a Masters degree and two a PhD. With respect to their major program of study, the students were then categorized into "Types," formed by placing similar majors in a general category. Thus, the "Sciences/Math Type" would be composed of people with majors in biology, chemistry, computer science, mathematics, and so on. The "Arts Type" would contain people from Drama, Music, Music Therapy, and the Visual Arts. The "Psychology Type" was made up of Psychology majors along with related areas like Criminology, Child Studies, and so on. The grouping allowed for a more manageable number of categories and a substantial number of participants within each category.

\subsubsection{Test Instruments}

(1) The Leisure Interests Checklist (LIC) [29]. The LIC was designed to tap into the recreational preferences of individuals. It was comprised of 135 items listed in an apparent random order. On the original LIC, the respondent's degree of interest is indicated by checking the appropriate column of a 4-point Likert scale: "Very Much": 3, to "Not at All": 0. In the present study the scale was modified in order to assess frequency of participation, rather than level of interest with wording changed from the active to the passive voice. The original 4-point Likert scale has been changed to a 5-point Likert scale to parallel the rating format of both instruments used in this study. While the original LIC contained interestlevel descriptors ("Very Much," "Much," "A Bit," and "Not at All"), the modified version contains frequency descriptors: "Regularly": 5, "Often": 4, “Occasionally": 3, "Rarely": 2; and "Never": 1.

To reduce the responses to manageable categories, we considered three-taxonomies. There are various taxonomies for understanding leisure preferences ranging from Passmore and French's [30] three category system (achievement leisure, social leisure, and time-out leisure) through Overs' [31] ten categories to Tinsley and Eldredge's [32] 12 classes of Leisure Preferences (see Table 1).

Attempts to sort the questions from the LIC into one of the current taxonomies listed in Table 1 were conceptually problematic. The issue of overlap was evident, as was the problem of fitting some questions into more than one category. Nevertheless, the Tinsley and Eldredge [32] classification was most appealing, with the twelve categories they suggested, but the sorting problem remained. As a compromise we decided to rely upon factor analysis of 
the LIC responses and use the inherent structure in the questionnaire, regardless of what others were using in the field of leisure studies.

Our categorization, based on factor analysis, was set to generate 12 categories from the 135 -item questionnaire. We selected 12 categories to align with Tinsley and Eldredge [32]. Using varimax rotation and an item loading criterion or.4, the twelve factors generated were clear and logical in the factor analysis. The factors are listed in Table 1 for comparative purposes. (The constructed variables from this factor analysis are available from the authors upon request (Appendix A).)

(2) The Student Teacher Anxiety Scale (STAS) [9]. The STAS was developed in Britain to measure four orthogonal factors related to student teacher anxiety and their relationship to the level of pupil disruption during practice teaching. The four orthogonal factors are (1) evaluation anxiety, (2) pupil and professional concerns, (3) class control; and (4) practice teaching requirements. The modified version [10] has been revised in two ways. First, the language was altered to better reflect a Canadian situation. Secondly, the original seven-point Likert-type scale was changed to a five-point Likert scale. These researchers determined the instrument to be reliable based on an evaluation using Cronbach's alpha. Validity was not addressed. In the Canadian version, the four factors generated by factor analysis were related to basically the same four categories as the British version (i.e., evaluation, pedagogy, class management and staff relations).

2.1.3. Procedure. The participants were administered the tests in three groups, according to their classes within their teaching divisions: PJ, JI, or IS. The location of the administration was a large lecture theatre that seated about 280 students. Variables with multiple levels (e.g., marital status, academic major, etc.) were recoded into dummy variables to facilitate subsequent analyses particularly using multiple regression and discriminant function analysis.

\subsection{Results}

2.2.1. Leisure Preferences. The first analyses were designed to build a picture of the participants' leisure preferences as they related to three areas, which are categorized as (1) Demographics, (2) Social Structures, and (3) Academic Majors. To accomplish this, we ran first a series of correlational analyses.

(1) Demographics. Table 6 shows that there were numerous correlations (correlation coefficients for Demographic Characteristics and Leisure Activities are available from the authors upon request (Appendix B)) between leisure preferences and the five demographic variables of (i) sex, (ii) age, (iii) teaching division (PJ, JI, or IS), (iv) completed education level, and (v) native or nonnative speakers. Regarding sex differences, females were more involved in Crafts, Social Activities, House \& Family, Travel, and Church Work, whereas males were more involved in Sports, and
Entrepreneurial Business Activity. Regarding Age, younger students were more involved in Sports and Social Activities, while older students were into House \& Family and Entrepreneurial Business Activities. For Division, upper grade level teachers were showing lower ratings for Social Activities, House \& Family, Travel, and Church Work, but they did show higher ratings for Entrepreneurial Business Activity. Those with a masters' degree showed lower ratings for Sports and Church Work, but higher ratings for Games. Nonnative speakers of English scored higher on the Crafts category. Obviously, demographics warrant attention.

(2) Social Structures. Certain social structureswere also related to Leisure Preferences. (Correlation coefficients for Social Structure Characteristics and Leisure Activities are available from the authors upon request (Appendix C)). People categorized as Single showed higher ratings for Sports and Social Activities, but lower ratings for Crafts and House \& Family, logically. The Married category is the mirror image of this, generally. Those with children showed lower ratings for Sports, Social Activities, and Travel. They showed higher ratings for House \& Family leisure preferences, as do those who Own Their Own Home. Interestingly, though, those living alone, showed higher ratings for Animal Bonding types of Leisure Preferences.

(3) Undergraduate Major Types. Correlations were also notable between areas of undergraduate major and leisure. (Correlation coefficients for Academic Majors and Leisure Preferences are available from the authors upon request (Appendix D)). It is important to note that while the subject category might not be the actual major of study in which the individuals were enrolled, they have been generally categorized and are thus assigned to closely align with actual majors. Five areas which revealed correlations are (i) English, (ii) Science, (iii) Human Kinetics, (iv) Sociology, and (v) Psychology. English majors are not particularly interested in Sports. Science Types would seem to be less involved in Social leisure preferences, and more involved in the Entrepreneurial activities. Those in Human Kinetics, logically, are more interested in Sports and Adventure leisure preferences. Sociology types appear less interested in House \& Family leisure. One borderline effect may prove interesting in subsequent research with larger samples; Psychology majors were less active in Exotica, but Exotica did not show evidence of adequate reliability so we treat this as suspect.

2.2.2. Anxiety and Leisure Preferences. The second focus addressed the relationship between Leisure Preferences and the four categories of Anxiety: (1) evaluation anxiety (Evaluation), (2) pupil and professional concerns (Concerns), (3) class control (Control), and (4) practice teaching requirements (Pedagogy) Anxiety was also related to various leisure preferences. (Correlation coefficients for Four STAS Anxiety Scales \& Leisure Preferences are available from the authors upon request (Appendix E).) Pedagogy Anxiety correlated positively with Crafts and House \& Family, thus, it would seem that those involved in Craft activities and House \& Family activities are more concerned with respect 
to pedagogy. Similarly, those involved with House and Family activities and Social activities seem more concerned with Evaluation. The only negative correlation was between Control Anxiety and leisure preferences related to Cognitive Pursuits. In effect, those involved in Cognitive Pursuits as a Leisure Preference were less concerned about class management. Those anxious about Personal Relationships were showing higher Leisure Preferences ratings for Crafts, House \& Family activities, and Church activities.

While variables related to demographics, social structures, and educational experience did show significant and multiple correlations with leisure preferences, it appeared that anxiety was less dramatically related to leisure. Still hopeful that leisure preferences might have a mitigating influence on anxiety, the profile that has emerged here leans towards fixed factors like demographics, social structures and educational experiences as potentially more relevant than leisure interests and activities.

Accordingly, in order to examine these influences in terms of profile-building, we used exploratory stepwise multiple regression analyses to examine the explanatory potential for anxiety levels linked to five profiles: (1) leisure preferences (2) leisure preferences plus demographics, (3) leisure preferences plus social structures, (4) leisure preferences plus academic majors, and (5) a composite profile. The potential profiles differ as a function of source of anxiety (Pedagogy, Evaluation, Control, and Concerns). Because the Composite Profile was apparently the best profile for explaining variance (Pedagogy $11.1 \%$, Evaluation 19.7\%, Control 7.3\%, and Concerns $12.5 \%$ ), we turn to an examination of this Composite Profile, and the Leisure Preferences Profile, as valuable for predicting change in anxiety levels in Study 2. We adopt these two profiles since the Composite Profile shows various nonleisure preferences (demographics, social structures and academic background) as relevant and somewhat stronger predictors. The Leisure Preferences Profile permits a closer look at leisure preferences independent of nonleisure predictors.

\section{Study 2}

To examine the change in stress/anxiety as a function of leisure preferences the participants from Study 1 were invited to respond following practice teaching, laying the groundwork for a profile that might lead to a better understanding of teacher anxiety and leisure-related, anxiety reduction. Three subsequent facts influenced the form of analyses adopted. First, multiple regression analysis was precluded as a test for the composite profile for predictors of anxiety reduction since sample size was reduced more than expected. Second, when we computed anxiety reduction scores over time, in fact, a substantial portion, were actually showing increases in anxiety. This logically led to two categories of participants - those who improved over time (Better) and those who regressed over time (Worse). The third observation related to the relative importance of nonleisure variables like Demographics, Social Structures and Educational Experience. Thus, we opted to use Discriminant Function Analyses which allowed us to build a picture of variables that discriminated between those who showed improvement over time and those who did not. As working hypotheses, emerging from Study 1, we predicted (1) that situational variables (Demographics, Social Structures, and Educational Experiences) would be better discriminators than leisure preferences in the Composite Profile, and (2) that certain leisure preferences (House and Family, Travel, Social, Cognitive Pursuits and Games) would be better discriminators than other leisure preferences.

\subsection{Method}

3.1.1. Subjects. Of the 216 original participants, 136 responded. There were 99 females and 37 males with the same proportions regarding age distribution and Teaching Division as in Study 1, as confirmed by Crosstabs and ChiSquare analyses $(P>.05)$.

3.1.2. Instruments. The same STAS form as in Study 1 was administered to monitor current levels of anxiety regarding the four categories of Pedagogy, Evaluation, Control, and Concerns.

3.1.3. Procedure. Students were invited to complete the STAS during class time. Only those who participated in Study 1which was essentially a pretest-had questionnaires included in this second study. The score for each of the four scales at time 2 was subtracted from the score at time 1 , which means a positive number would indicate a decrease in anxiety, whereas a negative number would indicate an increase in anxiety. Two research questions were explored: (1) which leisure preferences discriminated between those who fared well during and after practice teaching? (2) What would a profile predicting anxiety reduction look like?

3.2. Results. While our primary interest was the relationship between leisure preferences and anxiety reduction, it is worth noting at this point (see Figure 1) that (1) Anxiety was the highest for Evaluation and the lowest for Control (means and standard deviations are reported in Table 2) (main effect for Scale, $F(3,133)=97.59, P<.001)$, (2) Anxiety decreased over time for all scales (main effect for Time, $F(1,133)=127.85, P<.001)$, and $(3)$ the decline was more dramatic for Pedagogy and Evaluation (interaction effect for Scale by Time, $F(3,399)=14.09, P<.001)$. What is masked in these effects is the emergence of two distinct groups in the sample-a group that showed decreases in anxiety, and a group that did not. In other words, a group which showed either stability or worsening anxiety. This phenomenon allowed us to explore to explore our emerging profile with respect to variables that discriminated between the two groups.

3.2.1. Discriminant Function Analyses for the Leisure Preferences Profile. For the discriminant function analyses the participants were grouped into two groups: (1) Better (showed improvement in anxiety over time) and (2) Worse (showed regression over time). This was structured for each 


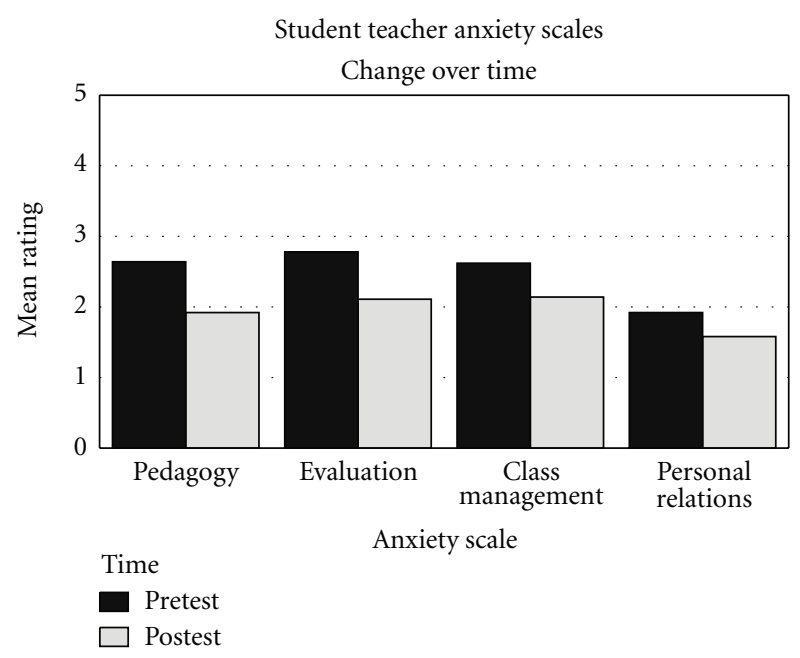

FIGURE 1: Showing the decrease in anxiety over time for each scale, and the more dramatic decrease in anxiety with respect to pedagogy and evaluation.

TABle 2: Means and standard deviations for four anxiety scales (STAS) at pretest and posttest.

\begin{tabular}{lcc}
\hline & Mean & SD \\
\hline STAS-Pedagogy Pretest & 2.64 & .74 \\
STAS-Pedagogy Posttest & 1.92 & .79 \\
STAS-Evaluation Pretest & 2.78 & .85 \\
STAS Evaluation Posttest & 2.11 & .82 \\
STAS-Class Management Pretest & 2.62 & .81 \\
STAS-Class Management Posttest & 2.14 & .76 \\
STAS-Personal Relationships Pretest & 1.92 & .93 \\
STAS-Personal Relationships Posttest & 1.58 & .72 \\
\hline
\end{tabular}

of the four anxiety scales. The twelve Leisure Preferences scales were entered as the predictor variables.

(1) Pedagogical Anxiety. The discriminant function analysis correctly classified $72.6 \%$ of the subjects and Wilks' Lambda (.822) was significant, $\chi^{2}(12)=22.75, P<.05$. Four leisure scales were discriminating between groups. (Table of Means and Standard Deviations for Leisure Preferences For Those Who Change over Time with Respect to Pedagogical Anxiety is available from authors upon request (Appendix F).) In effect, those reporting higher involvement in Sports, Social Activities, Adventure Activities, and Exotica did not fare as well with respect to anxiety reduction. From the Structure Matrix we see that the discriminant function correlates most highly with Sports (.680) followed by Adventure (.484), Exotica (.483), Social (.396), Cognitive Pursuits (.344), and Entrepreneurial Business Activity (.321). The remaining variables were all showing correlations less than 3 .

(2) Evaluation Anxiety. The discriminant function analysis correctly classified $74.4 \%$ of the subjects and Wilks' Lambda (.811) was significant, $\chi^{2}(12)=24.5, P<.025$. As may be seen in Table 16, four leisure scales were discriminating between groups. (Table of Means and Standard Deviations for Leisure Preferences for Those Who Change over time with Respect to Evaluation Anxiety is available from authors upon request (Appendix G).) Those reporting higher involvement in Social Activities, "Travel," Adventure Activities, and Exotica did not fare as well with respect to anxiety reduction. From the Structure Matrix we see that the discriminant function correlates most highly with Travel (.432) followed by Adventure (.405), Social (.382), and Exotica (.364). The remaining variables were all showing correlations less than 3.

(3) Class Management Anxiety. The discriminant function analysis correctly classified $70.2 \%$ of the subjects but Wilks' Lambda (.88) was not significant, $\chi^{2}(12)=14.82, P>.1$. However, the univariate analyses showed that two leisure scales were discriminating between groups. (Table of Means and Standard Deviations for Leisure Preferences for Those Who Change over time With Respect to Class Management Anxiety is available from authors upon request (Appendix $\mathrm{H})$.) Those reporting higher involvement in Crafts and Adventure did not fare as well with respect to anxiety reduction. From the Structure Matrix we see that the discriminant function correlates most highly with Adventure (.629) followed by Crafts (.546) and Travel (.360). The remaining variables were all showing correlations less than 3 .

(4) School-Based Interpersonal Relations Anxiety. The discriminant function analysis correctly classified $62.4 \%$ of the subjects but Wilks' Lambda (.90) was not significant, $\chi^{2}(12)=11.95, P>.1$. However, two leisure scales were discriminating between groups. (Table of Means and Standard Deviations for Leisure Preferences for Those Who Change over Time with Respect to School Based Interpersonal Relations Activity is available from authors upon request (Appendix I).) Those reporting higher involvement in Sports and Adventure did not fare as well with respect to anxiety reduction in this area. From the Structure Matrix we see that the discriminant function correlates most highly with Adventure (.603) followed by Travel (.593) and Social (.335). The remaining variables were all showing correlations less than 3.

The Leisure Preferences Profile does serve to discriminate for two of the four scales: Pedagogical anxiety and Evaluation anxiety. However, it was not the predicted variables that emerged as relevant discriminators or contributors to the discriminant function. Relevant variables were Sports, Social, Adventure, Exotica, Cognitive Pursuits, Travel, and Entrepreneurial Business Activity. Paradoxically, these leisure pursuit activities seem to function as distractors from the task at hand, or competitors to dealing with tasks, rather than relaxers.

3.2.2. Discriminant Function Analyses for the Composite Profile. For these discriminant function analyses the participants were grouped into two groups: those who showed improvement in anxiety over time (Better) and those who showed regression over time (Worse). The four dependent 
measures (Evaluation, Concerns, Control, and Pedagogy) were considered separately using 30 independent discriminating variables.

(1) Pedagogical Anxiety Reduction. In this analysis 19 subjects showed increases in anxiety (Worse) and 103 showed decreases (Better). The discriminant function analysis correctly classified $88.5 \%$ of the subjects and Wilks' Lambda (.582) was significant, $\chi^{2}(30)=56.79, P<.05$. Three leisure scales were discriminating with those who manifested increased anxiety showing higher scores in Leisure Preferences for Sports, Adventure, and Exotica, and also they were more likely to fall into the Science Type and Human Kinesiology Type of Academic Major. (Table of Means and Standard Deviations for the Composite Model Variables for Change over Time in Pedagogical Anxiety is available from the authors upon request (Appendix J).) In terms of demographics those for whom English was a second language were showing more anxiety as were those who lived alone. From the Structure Matrix we see that the discriminant function correlates most highly with Sports (.389) followed by Science as Major (.313). The remaining variables were all showing correlations less than 3 .

(2) Evaluation Anxiety Reduction. In this analysis 24 subjects showed increases in anxiety and 99 showed decreases. The discriminant function analysis correctly classified $79.7 \%$ of the subjects but Wilks' Lambda (.677) was not significant, $\chi^{2}(30)=41.31, P>.05$. Two leisure scales were discriminating with those who manifested increased evaluation anxiety showing higher scores in Leisure Preferences for "Travel" and Adventure and also those who were with Psych majors. (Table of Means and Standard Deviations for the Composite Model Variables for Change over Time in Evaluation Anxiety is available from the authors upon request (Appendix $\mathrm{K}$ ).) In terms of demographics, those who were speaking English as a Second Language (ESL) showed increases in Anxiety as did those who owned their own homes. From the Structure Matrix we see that all variables show correlation less than 3.

(3) Class Management Anxiety Reduction. In this analysis, 29 subjects showed increases in anxiety and 93 showed decreases. The discriminant function analysis classified $75.4 \%$ of the subjects but Wilks' Lambda (.708) was not significant, $\chi^{2}(30)=36.24, P>.1$. Two leisure scales did discriminate with those who manifested increased anxiety showing higher scores for Adventure and Crafts as did those with a Psych major. (Table of Means and Standard Deviations for the Composite Model Variables for Changes over Time in Class Managementis available from the authors upon request (Appendix L).) From the Structure Matrix we see that the discriminant function correlates most highly with Adventure (-.372) followed by Psych as Major (.357). The remaining variables all showed correlations less than 3 .

(4) Interpersonal Relations Anxiety Reduction. In this analysis 44 subjects showed increases in anxiety and 79 showed decreases. The discriminant function analysis classified $74.8 \%$ of the subjects but Wilks' Lambda (.681) was not significant, $\chi^{2}(30)=40.75, P>.05$. Nevertheless, two leisure scales were discriminating with those who manifested increased anxiety showing higher scores for Adventure and Sports activities. (Table of Means and Standard Deviations for the Composite Model Variables for Changes Over Time in Personal Relations Anxiety is available from the authors upon request (Appendix M).) Also, females were associated with anxiety reduction, more so than males. From the Structure Matrix we see that the discriminant function correlates most highly with Adventure (-.372) followed by Psych as Major (.357). The remaining variables all showed correlations less than 3 .

The Composite Profile was significant only with respect to Pedagogical Anxiety. Surprisingly, of those leisure preferences (i.e., Adventure, Sports, and Exotica) which did discriminate participants who showed reductions in anxiety from those who did not, it was Sports which showed the largest correlation with the discriminant function.

\subsection{Discussion}

3.3.1. The Profiles-Leisure Preferences Profile and Composite Profile. The first study revealed that a Leisure Preferences Profile (LPP) would be successful in predicting stress/anxiety, comprised specifically of the following Leisure Preferences, coupled with specific anxieties, House and Family, Cognitive Pursuits, and Games predict Pedagogical Anxiety, House and Family, Travel, and Social Interests predict Evaluation Anxiety, and House and Family predicts Concerns Anxiety. The LPP did not predict anxiety related to Control. Using the Composite Profile, the relevant variables were the following: Sex and Marital Status, which predict Pedagogical anxiety; Sex, Arts Major, and Travel predict Evaluation anxiety; Sex and Travel predict Control anxiety; Sex, Owning One's Home, and a Master's Degree predict Concerns anxiety. The second study demonstrated that this profile would be successful in a direction which actually proved to be contrary to expectations for discriminating between those who seemed to benefit from a particular leisure preference and those who did not: surprisingly, those with a more pronounced leisure preference for particular leisure activities (and, one can assume, greater leisure-type activities) were less likely to show a reduction in stress/anxiety. It is possible that the group which was less oriented to particular Leisure Preferences is investing its energy and activity in specifics related to pedagogy, class management, evaluation and so on, and that this proactive stance towards the source of stress is therefore more important for stress/anxiety reduction.

Consistent with such a proactive stance, the only circumstance in which involvement in a Leisure Preference seemed to negate anxiety was related to anxiety regarding Classroom Management and was the case for those who were interested in Cognitive Pursuits as a leisure activity: individuals who pursued cognitive-related leisure activities worried less about managing the classroom. It is plausible that individuals who are engaged in pursuits that are cognitive in nature, require attentiveness and insight, may be more readily distracted from concerns related to managing students in 
the classroom, particularly during their nonteaching time. In one study [21], encouraging the use of cognitive strategies as coping mechanisms in female students resulted in reduced negative emotions and tensions through cognitive self-talk, and thus, a reduction in anxiety. Interestingly, a more recent investigation [22] suggested that meaningful cognitive leisure activities may actually help to "turn off" work-related ruminations during nonwork periods. While this was not evident when examining the profiles using discriminant function analysis, the correlation may be worth attending to in future research.

With respect to our prediction that situational variables (Demographics, Social Structures, and Educational Experiences) would be better predictors of stress reduction than leisure preferences in a Composite Profile, the prediction failed. For Pedagogical anxiety the discriminating variables were Sports, Adventure and Exotica (Leisure variables), Academic Major (Science-Type and HK-Type), ESL, and Living Alone (Demographics). However, it was Sports which correlated most highly with the discriminant function. While the Composite Profile was not significant for the other three types of anxiety, the univariate analyses were indicative of differences related to Travel, Adventure, Crafts and Sports (Leisure Preferences), ESL, Psych Majors, and Sex (Situational variables).

That Sports is most highly correlated-meaning those most interested in Sports experienced more Pedagogical Anxiety than did others-may be that Sports Types are more inclined toward kinaesthetic pursuits and as such, worry less about external evaluation, studying, and being organized from a pedagogical perspective. Another logical perspective might simply be that Sports types are quite likely to be inclined to regular and consistent exercise and group activities. It may well be the case that a regular routine of exercise and extracurricular pursuits more naturally decreases generally stress.

Our second prediction, that certain leisure preferences (House and Family, Travel, Social, Cognitive Pursuits and Games) would be better predictors than others, was only partially supported in the Leisure Preferences Profile. For Pedagogy the observed order for discriminators was Sports, followed by Adventure, Exotica, Social, Cognitive Pursuits, and Entrepreneurial Business Activities. For Evaluation the observed order was Travel followed by Adventure, Social, and Exotica. The Leisure Preferences Profile was not significant for Class Management anxiety or Personal Relations anxiety. Since these leisure preferences were actually associated with increased stress/anxiety related to teaching, we suspect they serve as distracters from a more disciplined focus on mastery of educational practices that could cause stress. Admittedly, leisure activities may reduce actual physiological measures of stress, but the perceived stress of practice teachingthe cognitive stress-remains, and is actually intensified for some as a function of their leisure preferences.

Considering all the analyses (correlations, multiple regression analyses, discriminant function analyses, and univariate ANOVAs) in Study 1 and 2, it is of interest to address several effects that may hold potential for future research.
3.3.2. Sex. In spite of the growing body of leisure research, analyses of gender-related factors is surprisingly limited [33]. Nevertheless, there were a number of sex differences with respect to these variables. First, females were higher than males in leisure preferences that were related to Crafts, Social Activities, House \& Family, Travel, and Church Work. Males were higher in Sports and Entrepreneurial/Business Activities. Neither of these findings is surprising. In a study of adults, Caltabiano [23] found that females were higher than males on a cultural-hobbies factor, similar to the variables noted above in this previous study. Other researchers [34] note that, according to the literature, women are less physically active than men, generally less involved than men in activities outside the household, and are more time pressured than men. Miller and Brown [34] also point out that most literature in the area of women's leisure and constraints also attends to an ethic of care. While it is intuitive that both women and men who have children will have less leisure time available than those without children, it is still primarily a prevailing notion that women will be more constrained than men as a result of raising children.

Caltabiano [23] also reported that the males were higher on an outdoor-active sport factor, which aligns with the Sports factor of the present study. It is important to consider that for males Sports are often traditionally a socializing time for them (i.e., "pick up" basketball and hockey, spectator events, etc.). This also echoes Miller and Brown's [34] assertion that women are less physically active then men and that women decrease their involvement in physical activity at the time of certain life transitions, which includes starting work [35]. Given the age group of many of our participants, it is reasonable to assume that the majority of them are embarking on their first career.

In Study 1 we see, in the Composite Profile, that Sex is the most relevant predictor of anxiety levels. However, when we examine reduction in anxiety (Study 2), Sex was not a relevant discriminator, with the one exception of some minor relevance in anxiety reduction for Personal Relations anxiety, in which case females were showing greater anxiety reduction. Indeed, in the "Better" category we find $68.7 \%$ of the females, but only $45.9 \%$ of the males, Chi-square $=$ 5.94(1), $P<.025$.

3.3.3. Social Structures. That Single people were more interested in Sports and Social Activities is not surprising and was expected. The same can be said of the findings regarding participants who had children or owned their own home. One item of note, however, is that individuals who reportedly lived alone were higher in the Animal Bonding category of Leisure Preferences. Interestingly, Zasloff and Kidd [36] have reported that single women who lived with pets were less lonely than those who lived alone and that single women who lived with a dog were more attached to the pet than those who lived with other people. Other researchers have reported stress-related benefits attributed to adult-pet relationships $[37,38]$.

3.3.4. Undergraduate Majors. Differences related to undergraduate majors were interesting. A requirement for this 
teacher preparation program was that those enrolled had earned at least a Bachelor's degree. Not surprisingly, English majors were less interested in Sports, whereas those with a degree in Human Kinetics were more interested, although the latter were more interested in pet-related activities also. Perhaps a logical explanation for this is that individuals who own pets, particularly dogs or horses, are likely to participate more in outdoor activities, such as dog-walking and riding.

In the Composite Profile for predicting anxiety it was the Arts Majors only who were showing lower levels of anxiety and that was for Evaluation anxiety. It is possible that those in the Arts (Music, Drama, etc.) are used to being onstage and are therefore less stressed by being on-stage in a classroom. In the Composite Profile for exploring anxiety reduction it was the Science-Type and the HK-Type that were relevant for Pedagogy. For the Science-Type virtually all showed improvement ( 37 of 38 , or $97.4 \%$ ) whereas in the nonscience-type group only $80 \%$ showed improvement, Chisquare $=6.41(1), P<.025$. The HK-Type did not fare as well since only $68.4 \%$ of them were in the "Better" group whereas the non-HK-Type was much higher at $87.7 \%$, Chi-square = 4.75(1), $P<.05$. This is consistent with the discriminating Sports variable, in which those who were most involved with sports-related activities experienced the least anxiety reduction, with respect to Pedagogy.

The Psych Majors appeared to play a role with respect to Evaluation anxiety and Class Management anxiety. There were proportionally fewer Psych majors in the "Better" category for Evaluation anxiety change (65.2\%) compared to the non-Psych-Major group (82\%) but the difference was not statistically significant, Chi-square $=3.24(1), P=$ .07. In Class Management anxiety change the difference was significant ("Better" Category: Psych majors 56.5\%; non-Psych Majors 80\%), Chi-square $=5.74(1), P<.025$. These results are a little surprising as one would think students majoring in psychology would have a good sense of evaluation concepts and behaviour management skills and strategies.

3.3.5. ESL. As might be expected students who were not speaking English as their first language showed less improvement than native English speakers. This was true for three of the four anxiety scales (1) change in Pedagogical anxiety ("Worse" category: ESL: 29.6\%; non-ESL: 12\%), Chi-square: $5.01(1), P<.025$, (2) change in Evaluation anxiety ("Worse" category: ESL: 37\%; non-ESL: 17.4\%), Chi-square: 4.96 (1), $P<.05$, and (3) change in Class Management anxiety ("Worse" category: ESL: 42.3\%; non-ESL: 20.2\%), Chisquare: 5.56(1), $P<.025$. This may be related to what has been called "diversity-related burnout" [17], which is related to the negative effects of teachers striving to deal with a culturally heterogeneous classroom population. Given that the participants of this particular study were evaluated in part based on their teaching performance in an elementary classroom, it is logical that they would feel anxious over performing in this environment. Moreover, if their language skills had not remarkably improved by the end of the student teacher program - a time at which they are evaluated at a more critical level-it is understandable that their level of anxiety would have rapidly increased. Addressing the anxiety/stress levels of ESL student teachers would be one focus of future research that could be quite important, for both the student teachers and their pupils.

The research presented here does raise numerous potentially important research directions. Given the failure of our hope that certain leisure preferences (and assumed activities) would be conducive to anxiety/stress reduction, we would be reluctant to advocate leisure activities or practices for those indicating stress. Rather, we would be more likely to advocate cognitive activities associated with study, reading, and mastery of the tasks which are the source of anxiety. A closer examination of cognitive activities (readings, course work, role playing, etc.) and field experiences (classroom observation, practice teaching time, grade level taught, SES of students, experience level of associate teachers, etc.) that reduce anxiety would contribute to the predictive value of the profiles being developed here.

While our primary concern at this point would be the implications for student teachers, and education personnel who teach, or supervise, student teachers (e.g., implications related to course content, counselling, strategies for reducing stress and anxiety, and so on), the implications would also extend to the field of leisure studies. Indeed, our findings raise some significant questions for those working in the area of (1) leisure studies, (2) kinesiology, and (3) general stress and anxiety. The "end of leisure" as a stress/anxiety reducing strategy may be the wrong end. A better end might be the cessation of leisure as a strategy and the advocacy of cognitive activity for stress reduction. Thus, the end of leisure?

\section{References}

[1] R. S. Guglielmi and K. Tatrow, "Occupational stress, burnout, and health in teachers: a methodological and theoretical analysis," Review of Educational Research, vol. 68, no. 1, pp. 61-99, 1998.

[2] R. M. W. Travers, W. Rabinowitz, and E. Nemovicher, "The anxieties of a group of student-teachers," Education Administration \& Supervision, vol. 38, pp. 368-375, 1952.

[3] J. B. Davis, "Stress among secondary school student teachers: factors which contribute to it and ways of reducing it," The High School Journal, vol. 73, no. 4, pp. 240-244, 1990.

[4] Y. Gold, "Does teacher burnout begin with student teaching?" Education, vol. 105, no. 3, pp. 254-257, 1985.

[5] J. J. Hourcade, H. P. Parette Jr., and T. J. McCormack, "Stress sources among student teachers," Clearing House, vol. 61, pp. 347-350, 1988.

[6] R. Munday, R. Windham, C. Cartwright, and R. Bodenhamer, "Stress management training for preservice secondary teachers," Journal of Instructional Psychology, vol. 22, no. 2, pp. 141145, 1995.

[7] E. M. Wadlington, E. Slaton, and M. E. Partridge, "Alleviating stress in pre-service teachers during field experiences," Education, vol. 119, no. 2, pp. 335-348, 1998.

[8] W. F. Admiraal, F. A. J. Korthagen, and T. Wubbels, "Effects of student teachers' coping behaviour," British Journal of Educational Psychology, vol. 70, no. 1, pp. 33-52, 2000.

[9] N. I. Hart, "Student teachers' anxieties: four measured factors and their relationships to pupil disruption in class," Educational Research, vol. 29, no. 1, pp. 12-18, 1987. 
[10] L. L. Morton, R. Vesco, N. H. Williams, and M. A. Awender, "Student teacher anxieties related to class management, pedagogy, evaluation, and staff relations," British Journal of Educational Psychology, vol. 67, no. 1, pp. 69-89, 1997.

[11] T. Bachkirova, "Teacher stress and personal values: an exploratory study," School Psychology International, vol. 26, no. 3, pp. 340-352, 2005.

[12] R. P. Hastings and M. S. Bham, "The relationship between student behaviour patterns and teacher burnout," School Psychology International, vol. 24, no. 1, pp. 115-127, 2003.

[13] C. Montgomery and A. A. Rupp, "A meta-analysis for exploring the diverse causes and effects of stress in teachers," Canadian Journal of Education, vol. 28, no. 3, pp. 458-486, 2005.

[14] J. Head, F. Hill, and M. E. G. Maguire, "Stress and the post graduate secondary school trainee teacher: a British case study," Journal of Education for Teaching, vol. 22, no. 1, pp. 7184, 1996.

[15] S. A. Seidman and J. Zager, "The teacher burnout scale," Educational Research Quarterly, vol. 11, no. 1, pp. 26-33, 1987.

[16] D. Fontana and R. Abouserie, "Stress levels, gender and personality factors in teachers," The British Journal of Educational Psychology, vol. 63, pp. 2261-270, 1993.

[17] M. Tatar and G. Horenczyk, "Diversity-related burnout among teachers," Teaching and Teacher Education, vol. 19, no. 4, pp. 397-408, 2003.

[18] C. Kyriacou, "Teacher stress: directions for future research," Educational Review, vol. 53, no. 1, pp. 27-35, 2001.

[19] C. Maslach, "Job burnout: new directions in research and intervention," Current Directions in Psychological Science, vol. 12, no. 5, pp. 189-192, 2003.

[20] W. J. G. Evers, W. Tomic, and A. Brouwers, "Burnout among teachers: students' and teachers' perceptions compared," School Psychology International, vol. 25, no. 2, pp. 131-148, 2004.

[21] B. D. Payne and B. H. Manning, "The effect of cognitive selfinstructions on preservice teacher's anxiety about teaching," Contemporary Educational Psychology, vol. 15, no. 3, pp. 261267, 1990.

[22] M. Cropley and L. J. M. Purvis, "Job strain and rumination about work issues during leisure time: a diary study," European Journal of Work and Organizational Psychology, vol. 12, no. 3, pp. 195-207, 2003.

[23] M. L. Caltabiano, "Measuring the similarity among leisure activities based on a perceived stress-reduction benefit," Leisure Studies, vol. 13, pp. 17-31, 1994.

[24] J. G. Beard and M. G. Ragheb, "Measuring leisure satisfaction," Journal of Leisure Research, vol. 12, no. 1, pp. 20-33, 1980.

[25] M. P. Pondé and V. S. Santana, "Participation in leisure activities: is it a protective factor for women's mental health?" Journal of Leisure Research, vol. 32, no. 4, pp. 457-472, 2000.

[26] L. Patterson, "Participation in leisure activities by older adults after a stressful life event: the loss of a spouse," International Journal of Aging and Human Development, vol. 42, no. 2, pp. 123-142, 1996.

[27] M. G. Ragheb and J. McKinney, "Campus recreation and perceived academic stress," Journal of College Student Development, vol. 34, no. 1, pp. 5-10, 1993.

[28] L. Trenberth, P. Dewe, and F. Walkey, "Leisure and its role as a strategy for coping with work stress," International Journal of Stress Management, vol. 6, no. 2, pp. 89-103, 1999.
[29] T. L. Rosenthal, L. M. Montgomery, W. R. Shadish, and K. L. Lichstein, "Leisure interest patterns and subjective stress in college students," Behaviour Research and Therapy, vol. 27, no. 1, pp. 59-64, 1989.

[30] A. Passmore and D. French, "Development and administration of a measure to assess adolescents' participation in leisure activities," Adolescence, vol. 36, no. 141, pp. 66-75, 2001.

[31] R. P. Overs, "Avocational counseling," Counseling Psychologist, vol. 7, no. 2, pp. 85-88, 1977.

[32] H. E. A. Tinsley and B. D. Eldredge, "Psychological benefits of leisure participation: a taxonomy of leisure activities based on their need-gratifying properties," Journal of Counseling Psychology, vol. 42, no. 2, pp. 123-132, 1995.

[33] Y. Iwasaki, K. MacKay, and J. Mactavish, "Gender-based analyses of coping with stress among professional managers: leisure coping and non-leisure coping," Journal of Leisure Research, vol. 37, no. 1, pp. 1-28, 2005.

[34] Y. D. Miller and W. J. Brown, "Determinants of active leisure for women with young children-an "ethic of care" prevails," Leisure Sciences, vol. 27, no. 5, pp. 405-420, 2005.

[35] W. J. Brown and S. G. Trost, "Life transitions and changing physical activity patterns in young women," American Journal of Preventive Medicine, vol. 25, no. 2, pp. 140-143, 2003.

[36] R. L. Zasloff and A. H. Kidd, "Loneliness and pet ownership among single women," Psychological Reports, vol. 75, no. 2, pp. 747-752, 1994.

[37] N. R. Fawcett, R. Fawcett, and E. Gullone, "Cute and cuddly and a whole lot more? A call for empirical investigation into the therapeutic benefits of human-animal interaction for children," Behaviour Change, vol. 18, no. 2, pp. 124-133, 2001.

[38] M. Wells and R. Perrine, "Critters in the cube farm: perceived psychological and organizational effects of pets in the workplace," Journal of occupational health psychology, vol. 6, no. 1, pp. 81-87, 2001. 


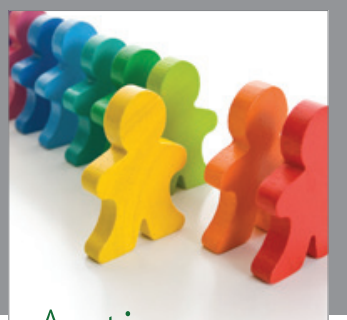

Autism

Research and Treatment
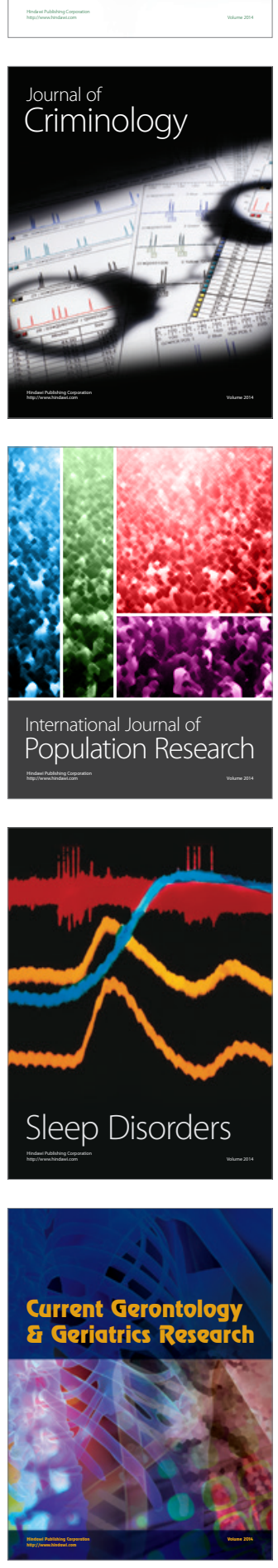
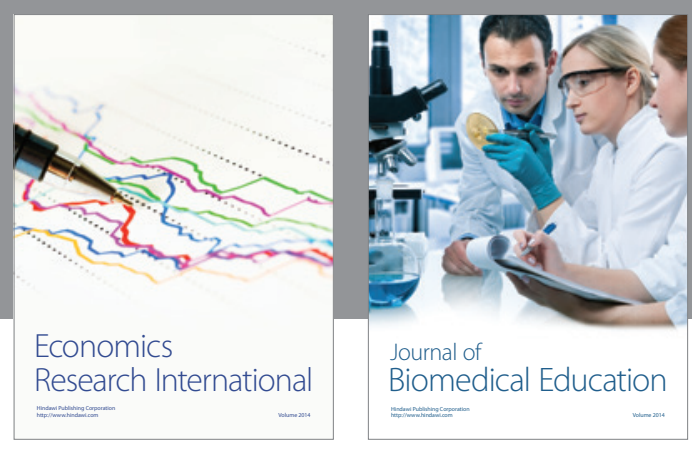

Journal of

Biomedical Education

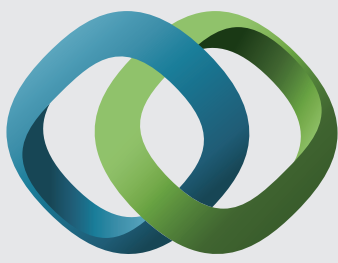

\section{Hindawi}

Submit your manuscripts at

http://www.hindawi.com
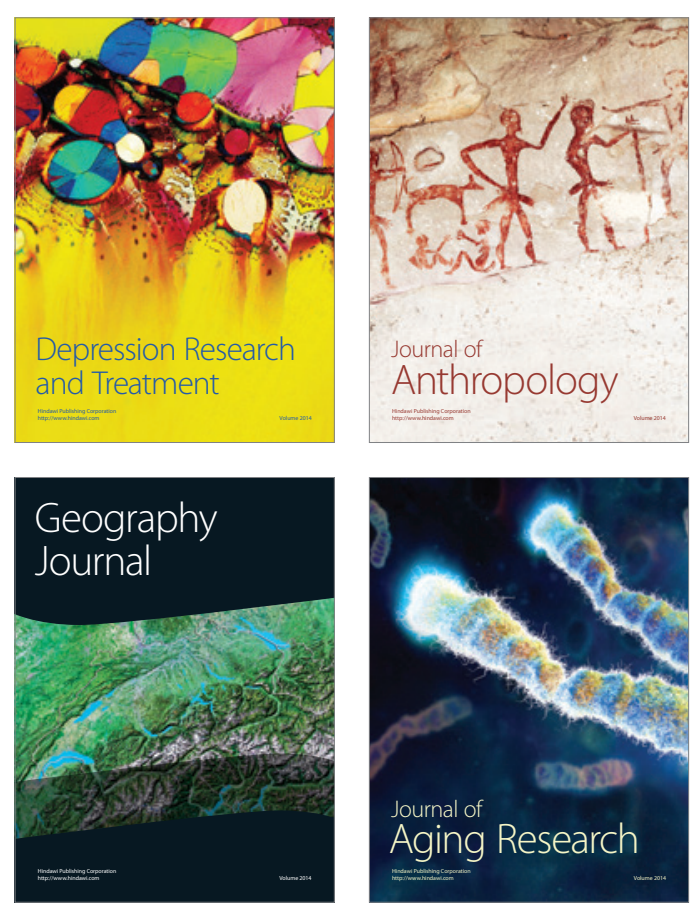

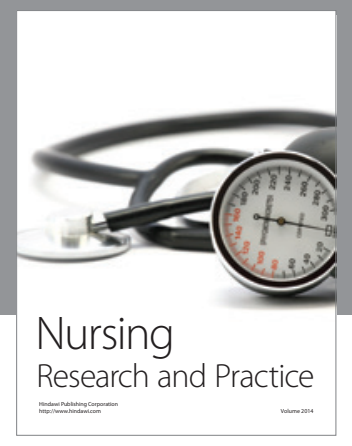

Nursing

Research and Practice

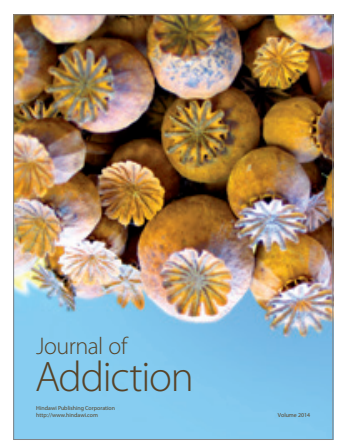

Child Development

Research

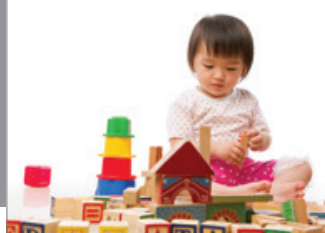

迥
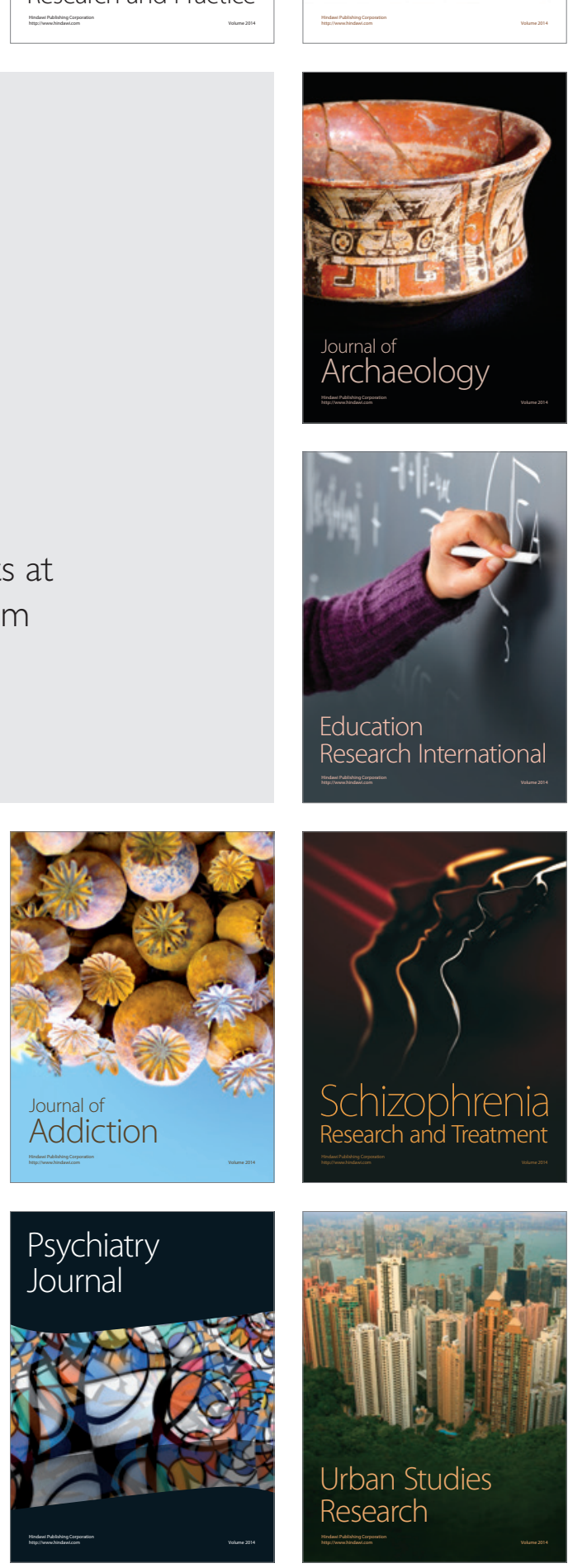